\title{
ROBUSTNESS OF SUBJECTIVE WELFARE ANALYSIS IN A POOR DEVELOPING COUNTRY: MADAGASCAR 2001
}

\author{
Michael Lokshin, Nithin Umapathi and Stefano Paternostro*
}

\begin{abstract}
We analyze the subjective perceptions of poverty in Madagascar in 2001 and their relationship to objective poverty indicators. We base our analysis on survey responses to a series of subjective perception questions. We extend the existing empirical methodology for estimating subjective poverty lines on the basis of categorical consumption adequacy questions. Based on this methodology we calculate the household-specific, subjective poverty lines and compare the poverty profiles derived from different subjective welfare questions. Our results show that the aggregate poverty measures derived from consumption adequacy questions accord quite well with the poverty measures based on objective poverty lines. The subjective welfare analysis can be used in poor developing countries for evaluating socioeconomic and distributional impacts of various policy interventions
\end{abstract}

Key words: Poverty, Subjective welfare, Africa, Madagascar

World Bank Policy Research Working Paper 3191, January 2004

The Policy Research Working Paper Series disseminates the findings of work in progress to encourage the exchange of ideas about development issues. An objective of the series is to get the findings out quickly, even if the presentations are less than fully polished. The papers carry the names of the authors and should be cited accordingly. The findings, interpretations, and conclusions expressed in this paper are entirely those of the authors. They do not necessarily represent the view of the World Bank, its Executive Directors, or the countries they represent. Policy Research Working Papers are available online at http://econ.worldbank.org.

* Corresponding authors: Nithin Umapathi, World Bank, 1818 H Street, NW, Washington, DC 20433, email numapathi@worldbank.org; Michael M. Lokshin, World Bank, email mlokshin@worldbank.org; Stefano Paternostro, World Bank, email: spaternostro@worldbank.org.

We thank Martin Ravallion, Emanuella Gallaso, Jed Friedman for useful comments and suggestions, and Mattia Romani for constructive comments and help with the data. 


\section{Introduction}

Interest in the study of subjective perceptions of well being has grown during the last 30 years. The recognition of the complementarities between subjective and objective poverty analysis has led to increasing attempts to integrate the two approaches. Income-based objective welfare indicators often fail to account for important socio-economic factors that could affect the level of a household's well being. The effect of some of these factors could be difficult to measure, while others are inherently unobservable. For example, such characteristics as anticipation of future shocks, household's perception of income security, perception about changes in the household's needs over the lifecycle, and the relativity component of household welfare are reflected in the subjective measures of well being, but omitted from the objective measures. Subjective poverty analysis providing additional information on characteristics of the poor could help designing better-targeted poverty alleviation policy and can be effectively used for cross-validation of objective poverty profiles.

Most of the empirical studies in this area, however, are based on data from developed countries and rely on Minimum Income Question (MIQ) methodology ${ }^{1}$. It is only recently that economists have turned their attention to analysis of subjective well being in developing countries and transition economies. Ravallion and Lokshin (2001, 2002) and Jovanovic and Milanovic (2000) deal with subjective welfare assessments in Russia. Pradhan and Ravallion (2000) assess subjective poverty in Jamaica and Nepal. These authors, as well as Deaton and Zaidi (2002), indicate that MIQ methodology might not be applicable to most developing countries, where income is not a well-defined concept, particularly in rural areas. To overcome this problem, Pradhan and Ravallion develop a qualitative model of perceived consumption needs that identifies the subjective poverty line without the MIQ.

How robust are the results of subjective welfare analysis in poor developing countries? Which methods for analyzing subjective welfare are more informative in poor countries and how well do poverty profiles derived from the subjective approach

\footnotetext{
$1 \quad$ See, for example, studies by Easterlin (1974), Van Praag and Kapteyn (1973); more recent works by Hagenaars (1986), De Vos and Garner (1991), Di Tella et al. (2001), Frey and Stutzer (2002), Oswald (1997), and Van Praag and Frijters (1999); the Special Issue of Journal of Economic Behavior and Organization, Vol 51(1); and van Praag, Frijters, and Ferrer-i-Carbonell (2003)
} 
correspond with those derived from the objective approach? In this paper we try to find the answers to these questions. Using data from the Madagascar Household Survey, we compare poverty profiles derived from different types of subjective welfare questions. We demonstrate that subjective welfare analysis based on consumption-adequacy questions produces sensible and robust results that correspond well with conventional, objective poverty analysis. At the same time, we find that MIQ-based poverty lines do not seem to generate sensible poverty profiles; they show only a weak correspondence to both objective and subjective poverty measures. To our knowledge, our paper presents the first comparative analysis of various methods of constructing subjective poverty lines in a poor developing country.

Madagascar is the seventh poorest country in the world today (World Bank 2002), and as such it serves as a definitive test for our adaptation of subjective poverty analysis to poor countries. Almost 80 percent of the Malagasy population lives in rural areas. Agriculture, including fishing and forestry, is a mainstay of the economy, accounting for one-third of GDP and employing four-fifths of the population. During the second half of the last century Madagascar was plagued with natural disasters, crop failures, epidemics, and political and economic crises. Poorly conceived government policies contributed to a long-term economic decline. Between 1993 and 1997 per capita GDP fell by about 1 percent annually, leading to a poverty rate of almost 80 percent by 1997. Despite a subsequent decrease in the poverty rate to 69 percent, population growth increased the number of poor people in Madagascar by 1.8 million between 1993 and 1999. The total number of poor people in Madagascar now stands at about 10.5 million (World Bank 2002).

The paper is organized as follows. The next section introduces data used in the analysis. Section 3 presents some descriptive statistics. Methodology and empirical specifications are discussed in Section 4. Section 5 presents our main results. Section 6 concludes. 


\section{Data and definitions}

The data for this study come from the 2001 Madagascar Household Survey (MHS). The MHS is a large-scale, multi-purpose survey of about 5,000 households that the Department for Household Statistics (DHS), National Statistical Institute, has conducted since 1993. ${ }^{2}$ The DHS collected the data for the latest MHS round in September, October, and November of 2001. They selected households for the survey sample through a multistage sampling technique. At the first stage, three strata were defined according to urban, rural, and semi-urban categories. Then 300 primary sampling units (PSUs) were selected from the strata with probability proportional to size. At the last stage, 16 to 18 households from each PSU were selected.

The MHS instrument combines features of a regular household budget survey with the features of an integrated living standard measurement survey. It collects information on demographic characteristics of household members, their labor market activities, and their health and education status. A large section of the questionnaire gathers detailed information on income and consumption expenditures as well as on ownership of assets.

In this paper we use total household consumption expenditure as a welfare indicator. Besides the traditional food and non-food components, the aggregate expenditure includes information on livestock, gifts, remittances, in-kind payments and in-kind consumption from non-farm activities. A measure of imputed rent is also included in the consumption aggregates for households that reported owning their houses. The consumption aggregates are deflated to account for regional price differences.

The objective poverty line in Madagascar is based on the cost-of-basic-needs $(\mathrm{CBN})$ method. The food poverty line is calculated as the cost of a food basket containing the minimum caloric intake of 2,133 calories per day. The composition of the food basket reflects the consumption patterns of the poorest three deciles of the population. To calculate the non-food component of the objective poverty line, the food poverty line is scaled up by the factor equal to the share of non-food consumption of households whose

\footnotetext{
2 Madagascar Household Survey rounds were conducted in 1993 (4,508 households), 1997 (6,350
} households), 1999 (5,120 households) and 2001 (5,080 households). 
total consumption is equal to the food poverty line (the so-called "lower poverty line", Ravallion 1998) ${ }^{3}$. No adjustments have been made to account for economies of scale arising from household size or for differences in nutritional requirements of the various age-gender groups.

A special section of MHS includes questions about the subjective well being of each household. ${ }^{4}$ A block of these questions deals with the adequacy of consumption expenditure for major consumption groups. The questions are formulated as follows:

Concerning your expenses relative to food, which of the following is true?

a. Your expenses are below the household's needs

b. Your expenses are on the average comparable to your household's needs

c. Your expenses exceed your household's needs

Similar questions are asked about expenses related to clothing, housing, and health. We call these the Consumption Adequacy Questions (CAQ). This paper is based on an analysis of answers to CAQs.

\section{Descriptive analysis}

The distribution of answers to CAQs for food, housing, clothing and health care are shown in Table 1. About half of Madagascar households indicated that their expenditures on food, clothing, and housing are less than adequate to meet the households' needs. For all the consumption categories less than 3 percent of the households perceived their expenditures as more than adequate.

Figure 1 shows how the subjective perceptions about the consumption adequacy depend on the level of household income. Approximately 60 percent of households from the lowest deciles of expenditure distribution consider their expenditure on food as inadequate. At the same time, that proportion is three times lower for the wealthiest households. A similar tendency could be observed for expenditures on clothing. Poor households are much more likely to categorize their expenditures on clothing as

\footnotetext{
3 For the detailed description of the methodology on constructing the welfare aggregate and objective poverty line in Madagascar, see Romani at el. (2003).

4 The questions in this module are asked at the household level. No information is available to identify the person who answers these questions. We assume that the household head replies to the questions concerning subjective well being of the household.
} 
inadequate compared to better-off households. The proportion of households with perceived inadequate expenditures on clothing declines from 80 percent for the lowest expenditure deciles to less than 20 percent for the highest deciles. Trends in perceived adequacy of housing and health expenditures reveal lower income elasticities for these consumption groups. In particular, the share of households who thought that their housing expenditures were inadequate stays almost constant up to the $60^{\text {th }}$ percentile of expenditure distribution.

The perceptions of consumption adequacy vary geographically. Table 2 presents the average proportion of households with less than adequate expenditures across different regions of Madagascar. The highest proportion of dissatisfied households is found in Western Madagascar. Over 60 percent of households in Toamasina and Fianarantsoa considered their food consumption inadequate. On the other hand, only about 42 percent of families living in Toliara and Antananarivo perceived their food expenditures as inadequate. The rankings of expenditure adequacy for housing and clothing show similar patterns. Sixty-seven percent of households in Toamasina and 65 percent of households in Fianarantsoa thought that they did not spend enough on clothing. Households living in Toliara and Antananarivo regions seemed to be more satisfied with their clothing expenditure levels. Overall, households from the poorest regions of Madagascar were less satisfied with expenditure levels than households from the richer regions.

Table 3 shows the proportion of households with inadequate consumption by type of household and consumption category. Again, general trends are clear - poor households were least satisfied with their level of consumption. In comparison with other household types, poor households consisting solely of elderly members had the lowest objective poverty rate (35 percent). Nonetheless, 53 percent of these households considered their food consumption inadequate. The poverty rate of extended households (88 percent) was almost twice that of elderly households, and 65 percent of such households indicated that their expenditures on food were inadequate. Single-parent households were among the least satisfied for almost all consumption categories. 


\section{Methodology}

The basic approach to subjective poverty analysis using CAQs was proposed by Pradhan and Ravallion (2000). They developed the method for calculating subjective poverty lines based on binary CAQs. The purpose of this section is to extend this methodology to cases with categorical CAQs.

We make a standard assumption that individuals are able to evaluate their satisfaction with levels of consumption in general, as well as evaluate their satisfaction using verbal qualifiers (Van Praag, Goedhart and Kapteyn 1980). We also assume that subjective assessments are comparable across respondents (Van Praag 1991). Given these assumptions, perceived satisfaction could depend on an individual respondent's own income, the so called "preference drift". It could also depend on individual characteristics of respondents and the characteristics of the households they live in (Ravallion and Lokshin 2002).

With these assumptions in mind, let $\mathbf{y}_{i}$ be a consumption vector with components $\mathrm{y}_{\mathrm{i} 1}, \ldots, \mathrm{y}_{\mathrm{iK}}$, and $\mathbf{x}_{i}$ be a vector of individual and household characteristics. A perceived minimum expenditure on good $k$ required to achieve an adequacy in consumption of good $k$ by household $i$ could then be expressed as:

$$
E_{i k}=g_{k}\left(\mathbf{y}_{i}, \mathbf{x}_{i}\right)+\varepsilon_{i k} \text { for } \forall k=1, \ldots, K ; i=1, \ldots, N
$$

where $g$ is a continuous function for all $k, K$ is the number of CAQs, $N$ is the sample size, and $\varepsilon_{i k}$ is an error term. Suppose $g_{k}$ satisfies the conditions of Brouwer's fixed-point theorem (e.g., Border 1985), then there exists a (not necessarily unique) solution $E_{i k}^{s}(x)$ of the equation:

$$
E_{i k}=g_{k}\left(E_{i k}, x_{i}\right) \text { for } k=1, \ldots, K
$$

$E_{i k}^{s}(x)$ is the expenditure on good $k$ at which, for a given $\mathbf{x}$, the subjective norms for good $k$ are met in expectation. The subjective poverty line (SPL) can be defined as the total expenditure that satisfies subjective norms for all $k$ goods. Under this definition SPL is:

$$
S P L_{i}\left(x_{i}\right)=\sum_{k=1}^{K} E_{k}^{s}\left(x_{i}\right)
$$


Assume that $E_{i k}$ has a lognormal distribution (Kapteyn, Koorman and Willemse 1988). If $g_{k}$ is linear in parameters, equation (1) could be expressed as:

$$
\log E_{i k}=\log \mathbf{y}_{i} \boldsymbol{\beta}^{k^{\prime}}+\mathbf{x}_{i} \boldsymbol{\varphi}^{k^{\prime}}+\varepsilon_{k i}
$$

where $\beta^{k}$ and $\varphi^{k}$ are vectors of parameters. From (2), a vector of subjective minimums for $k$ goods $\mathbf{E}^{\mathrm{s}}$ could be derived:

$$
\log \mathbf{E}^{s}=\mathbf{B}^{-1}\left(\boldsymbol{\Phi}^{\prime} \mathbf{x}\right) \text { where } \mathbf{B}=\left[\begin{array}{ccc}
1-\beta_{1}^{1} & \cdots & -\beta_{1}^{k} \\
\vdots & \ddots & \vdots \\
-\beta_{k}^{1} & \cdots & 1-\beta_{k}^{k}
\end{array}\right] \text { and } \mathbf{\Phi}=\left[\begin{array}{c}
\boldsymbol{\varphi}^{1} \\
\vdots \\
\boldsymbol{\varphi}^{k}
\end{array}\right]
$$

The SPL is calculated by (3) as a sum of subjective norms for all $k$ goods. However, in this specification we cannot estimate SPL directly because $E_{i k}$ is latent. Even if we collect information on consumption norms $E_{i k}$, the answers to such questions could be subject to large measurement errors (Pradhan and Ravallion 2000). We use responses to CAQs for our analysis of subjective poverty.

The observable qualitative adequacy variable $E_{i k}^{*}$ has three distinct categories arising from a single continuous indicator $E_{i k}$. The lower the value of $E_{i k}$, the more likely it is that a household's expenses will be below the adequacy level. Corresponding to these three categories we might define two cutoff points $\mu_{1 k}$ and $\mu_{2 k}$, such that someone with $\log E_{i k} \leq \mu_{1 k}+\log y_{k i}$ will find consumption of good $k$ less than adequate; someone for whom $\log y_{i k}+\mu_{1 k}<\log E_{i k} \leq \log y_{i k}+\mu_{2 k}$ will find consumption of that good adequate; and someone for whom $\log E_{i k} \leq \log y_{i k}+\mu_{2 k}$ will find consumption more than adequate. Assuming that $\varepsilon$ in (4) is normally distributed with distribution function $F$, we can use the ordered probit specification to model the qualitative responses on the consumption norm questions:

$$
\begin{aligned}
\operatorname{Pr}\left(E_{i k}^{*}=1\right)= & F\left(\mu_{1 k}+\left(1-\beta_{k}^{k}\right) \log y_{i k}-\boldsymbol{\beta}_{(-k)}^{k} \mathbf{y}_{i(-k)}-\boldsymbol{\varphi}^{\prime k} \mathbf{x}_{\mathbf{i}}\right) \\
\operatorname{Pr}\left(E_{i k}^{*}=2\right)= & F\left(\mu_{2 k}+\left(1-\beta_{k}^{k}\right) \log y_{i k}-\boldsymbol{\beta}_{(-k)}^{k} \mathbf{y}_{i(-k)}-\boldsymbol{\varphi}^{\prime k} \mathbf{x}_{\mathbf{i}}\right)- \\
& F\left(\mu_{1 k}+\left(1-\beta_{k}^{k}\right) \log y_{i k}-\boldsymbol{\beta}_{(-k)}^{k} \mathbf{y}_{i(-k)}-\boldsymbol{\varphi}^{\prime k} \mathbf{x}_{\mathbf{i}}\right) \\
\operatorname{Pr}\left(E_{i k}^{*}=3\right)= & 1-F\left(\mu_{2 k}+\left(1-\beta_{k}^{k}\right) \log y_{i k}-\boldsymbol{\beta}_{(-k)}^{k} \mathbf{y}_{i(-k)}-\boldsymbol{\varphi}^{\prime k} \mathbf{x}_{\mathbf{i}}\right)
\end{aligned}
$$

From this model we obtain the estimates of parameter vectors $\beta, \varphi, \mu_{1}$ and $\mu_{2}$. While these estimates are identified only up to a constant, we can, from (5), solve the system of $k$ equations for a vector of subjective norms for $k$ goods as: 


$$
\log \mathbf{E}_{\mathbf{i}}^{s}=\mathbf{B}^{-1}\left(\boldsymbol{\mu}_{1}-\boldsymbol{\Phi}^{\prime} \mathbf{x}_{\mathbf{i}}\right)
$$

The SPL is then calculated using (3). In the empirical part of this paper we call this approach of calculating the subjective poverty line and the corresponding estimations as Method 1.

The CAQs in the Madagascar survey do not cover the whole range of possible goods and services consumed by households. For example, in addition to expenditures on food, clothing, housing and health, households also report expenditures on durables, private transfers, education, transportation, and so on. Thus, the subjective poverty lines derived from Method 1 should be adjusted upwards to account for these missing nonfood consumption components. We calculate a scaling-up factor using the share of combined expenditure on food, housing and clothing spent by households around the poverty line.

An alternative approach to calculating the SPL is based on regressing the food CAQs on total household expenditure and other household characteristics. This SPL determines the level of total expenditure that would satisfy household food requirements. This approach resembles one commonly used in applied work: the "Food Energy Intake" method (e.g., Dandekar and Rath 1971, Greer and Thorbecke 1986). In the paper, we refer to this approach as Method 2.

The empirical specifications of the ordered probit estimations (6) are similar for all methods. In Method 1 we use categorical answers to CAQs for food, housing and clothing as the dependent variables. The CAQ for food expenditures is the dependent variable in the Method 2 estimation. The set of explanatory variables (shown in Table 4) includes household demographic variables, variables reflecting the level of education, working status, religion of household members, regional and urban/rural dummies, and the variable indicating the average level of consumption and the level of consumption inequality (Gini) in the PSU.

\section{Results}

In this section we present first the ordered probit estimations for model (6) and then the poverty statistics and poverty profiles derived from these estimations. 
Table 5 shows the ordered probit results for two empirical specifications corresponding to Methods 1 and 2. With Method 1, the variables representing household consumption of food, housing, and clothing have strong positive and statistically significant effects on perceived consumption adequacy. The demographic composition also affects household perceptions of expenditure adequacy. Controlling for household composition and expenditure level, households with a larger share of young $(15-24)$ and prime-age $(25$ - 59) women have more positive perceptions of food expenditure adequacy. One explanation for this might be that women use food more efficiently because they have a comparative advantage in home production relative to men. The presence of children has a negative and statistically significant effect on household perceptions of housing expenditure adequacy. Households with children could be anticipating the increasing need for housing when the children grow up. This expectation would decrease the current level of satisfaction with housing expenditures. Households with sick members are more likely to perceive their expenditures on food, housing and clothing as inadequate compared with an average household in the sample. A higher share of unemployed members also decreases household satisfaction with food expenditures. Religious beliefs do not seem to have a significant effect on household perceptions of consumption adequacy. Rural households are more satisfied with the levels of expenditures on food and housing relative to urban households. The estimations also reveal strong regional differences in consumption adequacy perceptions.

The ordered probit estimations show the importance of income distribution within a community in assessments of consumption adequacy. Households living in population clusters with a high mean income are more likely to perceive their food, housing, and clothing consumption expenditures as less adequate compared to an average household. Higher intra-cluster inequality negatively affects perceptions of food consumption adequacy, but does not have a significant effect on perceptions of housing and clothing consumption adequacy. 


\section{Subjective poverty profiles}

We can now derive the subjective poverty lines using the probit estimates. We propose two versions of the SPL for Method 1. In the first version we use CAQ responses for food, clothing and housing (Equation 7 in the methodology section) to calculate the SPL. However, the SPL component computed for clothing expenditure adequacy shows significant instability ${ }^{5}$. Purchases of clothing are relatively rare in Madagascar (12 percent of households reported no expenditure on clothing during the three months preceding the survey) and the relation between actual expenditures and perceived consumption adequacy could be weak. For that reason, the second version excludes CAQ responses for clothing and relies only on responses regarding food and housing adequacy.

We will refer to the two subjective poverty lines obtained with Method 1 as CAQ1A and CAQ1B, and the food-based SPL obtained with Method 2 as CAQ2. To calculate the poverty measures we compare consumption aggregates with objective (absolute) and subjective poverty lines. The households whose per capita expenditures are below a particular poverty line are categorized as poor.

Table 6 shows the poverty headcounts and poverty headcount rankings for six regions of Madagascar and for the country as a whole. About 80 percent of households in Madagascar could be classified as poor using the CAQ1A subjective poverty line. The poverty headcount is about 58 percent according to CAQ1B. The national poverty rate derived from Method 2 falls between these two estimates (67 percent). Regional poverty profiles calculated with these three methods show large variability as well. The second column in Table 6 ranks regions in Madagascar according to objective poverty rates. According to the regional poverty profile, Fianarantsoa has the highest objective poverty rate of about 83 percent and it is ranked $6^{\text {th }}$ (the poorest) on the objective poverty ranking scale. Antananarivo has the lowest poverty rate and poverty rank. One of the subjective poverty lines produces rankings that are different from the objective results. For example, Fianarantsoa and Toamasina are the poorest regions according to CAQ1B and CAQ2, whereas CAQ1A ranks these two regions as the third and fourth poorest. The poverty

$5 \quad$ Pradhan and Ravallion (2000) also exclude clothing from the SPL calculation, indicating that allowances for clothing fluctuate wildly for different households in Nepal. 
rankings produced by subjective Methods $1 \mathrm{~B}$ and 2 (CAQ1B and CAQ2) are similar to the objective poverty rankings. But subjective Method 1A produces regional poverty profiles that differ considerably from the other subjective and the objective profiles.

The changes in objective and subjective poverty rates due to household size are presented in Figure 2. In the background of Figure 2 we show the distribution of households by size. The proportion of households with per capita expenditures below the objective poverty line increases with household size almost monotonically. Less than a quarter of individuals living alone are poor according to the objective poverty measure. The poverty rates for households with seven or more members exceed 75 percent $^{6}$. Subjective poverty rates calculated with Method 2 closely follow the objective poverty trends. The rates are higher for small households, but the difference between objective and subjective poverty (Method 2) becomes insignificant for households with three or more members.

Overall, the poverty rate derived from Method $1 \mathrm{~A}$ is higher than the objective poverty rate and the subjective poverty rate derived from Method 2. Under Method 1A, the share of the poor reaches 80 percent among single-person households, declining to about 68 percent for households with four members. The number of families with per capita expenditures below the subjective poverty line defined by Method 1B increases as households increase in size.

The trends in the poverty rates calculated by the subjective and objective methods show different economies of scale at work in relation to household consumption adequacy. However, the objective poverty lines in Madagascar do not explicitly account for economies of scale because they are calculated on a per capita basis. The CAQ1A and B poverty lines show some economies of scale for households with 1 to 4 members. More members increase poverty, but at lower rates than those for objective and CAQ2 poverty lines.

Poverty profiles for households with different characteristics are shown in Table 7. While poverty levels differ depending on the method, in general the objective and subjective poverty profiles reveal similar tendencies. According to all poverty definitions,

6 Meaningful poverty comparisons could be made for households with up to 7 members. The estimates of the poverty rates for households with more then 8 members become imprecise because of the small number of such households in our sample. 
households headed by individuals with low levels of education are among the poorest. Poverty rates decline for households with better-educated heads. The number of poor households whose heads hold a university degree is close to zero. Households with heads employed in agriculture have the highest poverty rate across all poverty lines. Households with heads employed in the public sector or in services are better off. Ethnicity seems to be a strong determinant of household poverty. The lowest poverty rates are registered among Highland ${ }^{7}$ groups and foreigners, whereas the poorest households reside in the East and South East of Madagascar.

In some instances, subjective and objective poverty profiles draw quite different pictures. According to the objective poverty method the elderly enjoy the lowest levels of poverty ( 35.2 percent). However, the two Method 1 poverty lines show that the elderly are the poorest group (poverty headcounts of 98.7 and 98.0 percent, respectively, for CAQ1A and CAQ1B). Looking at the age-related poverty profiles, notice that the objective poverty rates are the lowest among households with young (16-24 year old) heads. The objective poverty headcounts reach a maximum of 70.3 percent for households headed by individuals 25 to 44 years of age and then decline for households with older heads. The subjective poverty lines, however, produce poverty rates that increase almost uniformly with age.

\section{Alternative subjective poverty lines}

There are two sets of questions in the Madagascar Household Survey that could also be used to obtain subjective poverty lines. One involves general satisfaction with different aspects of life:

With regard to the needs of your household to live marginally, are you satisfied in general about:
a. Food
b. Housing
c. Clothing
d. Health care

\footnotetext{
${ }^{7}$ Categories are as follows - Highlands: Merina, Betsileo; East: Betsimisaraka, Bezanozano, Sihanaka; South-East: Antambahoaka, Antefasy, Antemoro, Antesaka, Tanala; North: Sakalava, Tsimihety, Antakarana; South: Antandroy, Vezo, Mahafaly, Antanosy, Bara; Foreigners: Frantsay, Karana, Komoriana, Sinoa.
} 


\section{e. Your children's education (schooling)}

We refer to these questions as General Satisfaction Questions (GSQs). The other question - Minimum Income Question (MIQ):

\section{How much does your household need per month to live?}

In this section we will show how well the subjective poverty profiles derived from CAQ correspond to those based on MIQ and GSQ.

To calculate the subjective poverty line from binary GSQs we use the empirical framework developed by Pradhan and Ravallion (2000). While the wording of the satisfaction questions is different from the consumption adequacy questions, the meaning of the two sets of questions is quite similar. But we expect that the poverty estimates based on binary GSQs would be less precise than those based on categorical CAQs because the former provide less information about household welfare. For subjective poverty lines based on MIQ we used the standard "Leyden" method (van Praag and Warnaar 1997). To describe briefly our estimation approach, we first regress the answers to GSQs or MIQ on the set of explanatory variables used in our main model (Table 4). For GSQs we estimate a binary probit model, and for the MIQ we use an ordinary least squares regression ${ }^{8}$. In the second stage, in order to determine the SPL, we solve the estimated equations for a fixed point with respect to the welfare indicator. Households are classified as poor if their total per capita expenditures are less than the corresponding SPL. As we did with CAQ, we calculate three SPLs using responses to GSQs. The first subjective poverty line (Method 1A) is calculated as a sum of SPLs for food, housing and clothing, adjusting for the remaining non-food consumption with the Engel method. The second SPL (Method 1B) excludes clothing from the calculation. The third (Method 2) can be interpreted as the level of total expenditure at which food consumption is considered to be nutritionally adequate for good health and normal activity.

A comparison of regional and demographic poverty profiles for different methods of calculating the SPL shows that GSQ Methods 1B and 2 produce poverty profiles close to the objective profiles, but that GSQ Method 1A and MIQ do not.

\footnotetext{
8 The results of the probit and OLS estimations and corresponding poverty profiles are available from the authors on request.
} 
At the national level, poverty headcounts based on GSQ-derived poverty lines range from 58 percent for Method 1B to 98 percent for Method 1A, with 79 percent for Method 2. The MIQ-derived poverty headcount is about 76 percent. Figure 3 shows the changes in poverty due to household size that different methods estimate. The subjective poverty rates fluctuate much more than the subjective rates calculated using CAQ. Poverty rates based on GSQ Methods 1B and 2 increase with household size and are close to the poverty estimates based on CAQ. The MIQ poverty rates decline with household size. Poverty rates for GSQ Method 1A do not change with household size.

Table 8 summarizes our findings on the correspondence of the poverty estimates based on subjective and objective poverty lines. Each cell in the table gives the value of a Cramer's V statistic (Agresti 1984) that refers to the degree of association between the poverty categorizations resulting from two different estimation methods. If every household that is classified as poor by one method is also poor according to another method, the value of Cramer's V would equal one. On the other hand, if such poverty categories do not overlap, the value of Cramer's $\mathrm{V}$ is zero.

The poverty categorizations based on GSQ Method 1A and MIQ seem to be different from all other methods. The Cramer's V statistic for GSQ Method 1A is close to zero and does not exceed 0.360 for MIQ. But CAQ Method 2 and GSQ Method 2 produce a good match with objective poverty categorizations. It is interesting to note that the degree of association between these two methods is also very strong (Cramer's V of 0.947).

In recent years several economists have estimated household economies of scale using the subjective approach first suggested by Hagenaars and van Praag (1985). For instance, van Praag and Warnaar (1997) analyze data for several European countries and the United States and report elasticities of 0.17 for the Netherlands; 0.50 for Poland, Greece, and Portugal; and 0.33 for the United States. Among developing countries, Pradhan and Ravallion (2000) find elasticities of 0.47 for Nepal and 0.84 for Jamaica. Ravallion and Lokshin (2002) report a coefficient of 0.48 for household economies of scale in Russia.

Our assessment of the economies of scale using subjective welfare questions fails to produce reliable results. We find that the estimates are sensitive to the empirical 
specification of the model and the SPL methodology used. For example, CAQ Method 2 demonstrates no significant economies of scale (elasticity close to unity), but the MIQ method yields an economies of scale elasticity of 0.55 . These large fluctuations could be due to a correlation of household size with other factors that may also affect subjective welfare perceptions. It may not be possible to isolate the effect of household size from the effects of other variables in the model.

\section{Conclusions}

In this paper we present the analysis of subjective perceptions of poverty in Madagascar in 2001. We employ several survey instruments to calculate subjective poverty lines and compare the poverty profiles based on different methodologies. The aggregate poverty measures derived from CAQ subjective poverty lines accord quite well with the poverty measures based on objective poverty lines. MIQ-based poverty measures do not seem to produce sensible poverty profiles and demonstrate only a weak correspondence to both objective and other subjective poverty measures.

Our data on Madagascar in 2001 indicate a strong positive and significant correlation between self-rated economic welfare and household income. The households with higher per capita income are more likely to consider their expenditures as adequate and to be generally more satisfied with various aspects of their lives. However, income can explain only a part of the variation in a household's subjective well being. The relative income position of the household among its neighbors strongly affects perceived welfare. Controlling for own income and other characteristics, poor households living in high-income areas have lower perceived welfare than the average poor household in the sample. Objective, income-based approaches of measuring poverty might underestimate the extent of poverty in the richer areas and, in particular, underestimate poverty in urban areas (Ravallion and Bidani 1994). Demographic characteristics of the households also affect self-rated welfare. Households with a larger share of well-educated members and prime-age women have on average higher welfare perceptions. Households with sick and/or unemployed members report lower-than-average levels of subjective welfare. 
In several instances, subjective and objective poverty approaches produce quite different profiles. The objective poverty profiles tend to show a higher poverty rate than most of the subjective profiles and a higher incidence of poverty among younger families. Malagasy households, however, tend to perceive that poverty is more acute among older and smaller households. Another interesting finding is the diversion between objective and subjective poverty estimates for urban and rural areas. The objective approach shows a strong over-representation of the poor in rural areas. But subjective estimates reveal a higher level of satisfaction among rural households with regard to expenditures on food and housing. One explanation for this could be the underreporting of in-kind consumption in rural areas.

The fact that subjective and objective poverty numbers differ significantly across some dimensions must make one wary about the robustness of poverty comparisons based on absolute poverty lines alone. The problem of identifying the population groups that are in crucial need of government support is of increasing importance in Madagascar. Current anti-poverty programs in the country are based on a comparison of total household consumption expenditures with the cost-of-basic-needs type poverty line. The high poverty rates that result from this approach render almost any social protection initiatives very difficult to target. The results of the subjective poverty approach presented in this paper could provide an alternative view on the poverty situation in Madagascar and thus help to design better poverty alleviation policies and channel limited and increasingly scarce resources to their best uses.

The systematic and robust results, except for the estimation of economies of scale, that we found using the different approaches in one of the poorest countries in the world indicate that subjective poverty analysis can be used in poor developing countries for assessing various policy interventions and evaluating the tradeoffs between a household's monetary and non-monetary well being. 


\section{References}

Agresti, A., (1984) Analysis of Ordinal Categorical Data, New York: John Wiley and Sons

Border, K., (1985) Fixed Point Theorems with Applications to Economics and Game Theory, Cambridge, UK: Cambridge University Press

Dandekar, V., and N. Rath, (1971) Poverty in India. Pune: Indian School of Political Economy.

Deaton, A., and S. Zaidi (2002) "Guidelines for Constructing Consumption Aggregates for Welfare Analysis," LSMS Working Paper \#135, The World Bank, Washington, D.C.

De Vos, K., and T., Garner (1991) "An Evaluation of Subjective Poverty Definitions: Comparing Results from the U.S. and the Netherlands", Review of Income and Wealth, Vol.37: 267-85

Di Tella, R., MacCulloch R., and A.,Oswald (2001) "Preferences over Inflation and Unemployment: Evidence from Surveys of Happiness, American Economic Review Vol. 91: 335-341

Easterlin, R., (1974) "Does Economic Growth Improve the Human Lot? Some empirical evidence," In: David, P.A., Reder, M.W. (Eds.), Nations and Households in Economic Growth. Essays in Honor of Moses Abramowitz, Academic Press, New York, pp 89-125.

Frey, B., and A., Stutzer (2002), Happiness and Economics. Princeton and Oxford: Princeton University Press

Greer, J., and E. Thorbecke, (1986), "A Methodology for Measuring Food Poverty Applied to Kenya," Journal of Development Economics 24: 59-74

Hagenaars, A., and B., van Praag, (1985) "A Synthesis of Poverty Line Definitions" Review of Income and Wealth Vol. 17: 139-154

Hagenaars, A., and J. 1di, (1986) The Perception of Poverty, Amsterdam: North Holland

Kanbur, R., (2001) "Qual-Quant Qualitative and Quantitative Poverty Appraisal: Complementarities, Tensions and the Way Forward," Working Paper 2001-05, Department of Applied Economics and Management, Cornell University

Kapteyn, A., Kooreman, P., and R., Willemse, (1988) "Some Methodological Issues In The Implementation Of Subjective Poverty Definitions", The Journal of Human Resources Vol. 23: 222-242

Milanovic, B., and B., Jovanovic (1999) "Changes in the Perception of the Poverty Line during the Depression in Russia, 1993-96”, World Bank Economic Review Vol.13: 539-59

Oswald, A., (1997) “Happiness and Economic Performance”, Economic Journal 107: $1815-1831$

Pradhan, M., and M., Ravallion, (2000) "Measuring Poverty Using Qualitative Perceptions Of Consumption Adequacy", Review of Economics and Statistics Vol. 82: 462 - 471

Pollak, R., (1991) “Welfare Comparisons And Situation Comparisons", Journal of Econometrics Vol. 50: 31-48 
Pollak, R., and T., Wales, (1979) "Welfare Comparison and Equivalence Scale", American Economic Review Vol. 69(2): 216-221

Ravallion, M., (1998) "Poverty Lines in Theory and Practice," LSMS Working Paper \#133, The World Bank, Washington, D.C.

Ravallion, M., and M., Lokshin, (2002) "Self-Rated Economic Welfare in Russia," European Economic Review, Vol. 46: 1453-73

(2001) "Identifying Welfare Effects Using Subjective Questions," Economica, Vol. 68(271): 335-57

(2000) "Who Wants to Redistribute? The Tunnel Effect in 1990s Russia," Journal of Public Economics, Vol. 76(1): 86-104

Ravallion, M., and B. Bidani, (1994) "How Robust Is The Poverty Profile?" World Bank Economic Review, Vol. 8: 75-102

Rose, R., and I., McAllister (1996), "Is Money the measure of welfare in Russia?" Review of Income and Wealth, Vol. 1: 75-90

Slesnick, D., (1998) “Empirical Approaches To Measuring Welfare,” Journal of Economic Literature Vol. 36: 2108-65

van Praag, Bernard, (1991) "Ordinal and Cardinal Utility: An Integration of the Two Dimensions of the Welfare Concept," Journal of Econometrics, 50: 69-89

Van Praag, B., Goedhart T., and A. Kapteyn (1980), "The Poverty Line. A Pilot Survey in Europe," Review of Economics and Statistics, Vol. 62: 461 - 465

Van Praag, B., and M., Warnaar, (1997) "The Cost of Children and the Use of Demographic Variables in Consumer Demand," Chapter 6 in Mark Rosenzweig and Oded Stard, eds., Handbook of Population and Family Economics, 1A, Amsterdam, North-Holland: 241-73

Van Praag, B., Frijters, P., and A., Ferer-i-Carbonell, (2003) "The Anatomy of Subjective Well-Being", Journal of Economic Behavior \& Organization Vol. 51: 29-49

Van Praag, B., and P. Frijters, (1999) "The Measurement of Welfare and Well-being; the Leyden approach," In: Kahneman, D., Diener, E., Schwarz, N. (Eds.), Foundations of Hedonic Psychology, Scientific Perspectives on Enjoyment and Suffering. Russel Sage Foundation, New York

Van Praag, B., and M. Warnaar (1997) "The Cost of Children and the Use of Demographic Variables in Consumer Demand," In: Rozenzweig, M., and O. Stark, eds, Handbook of Population and Family Economics Vol. 1A, Chapter 6: 241-273

Van Praag, B., and A. Kapteyn, (1973) "Further Evidence on the Individual Welfare Function of Income, an Empirical Investigation in the Netherlands." European Economic Review, Vol. 4: 33-62

World Bank (2002) "Madagascar Poverty and Socio Economic Development: 19931999,” Report \#23366-MAG, The World Bank, Washington, D.C. 
Table 1: Perceived adequacy of consumption in Madagascar, proportion of population

\begin{tabular}{lccc}
\hline $\begin{array}{c}\text { Consumption } \\
\text { categories }\end{array}$ & $\begin{array}{c}\text { Less than } \\
\text { Adequate }\end{array}$ & $\begin{array}{c}\text { Just } \\
\text { adequate }\end{array}$ & $\begin{array}{c}\text { More than } \\
\text { Adequate }\end{array}$ \\
\hline Food & & & \\
Housing & 0.531 & 0.434 & 0.030 \\
Clothing & 0.522 & 0.453 & 0.020 \\
Health care & 0.638 & 0.346 & 0.011 \\
& 0.399 & 0.575 & 0.022 \\
\hline
\end{tabular}

Table 2: Regional differences in the proportion of households that consider their level of expenditures inadequate by consumption categories (standard errors)

\begin{tabular}{lccccc}
\hline & \multicolumn{5}{c}{ Adequacy of household expenditures } \\
\hline Regions & Food & Housing & Clothing & Health & Objective poverty \\
\hline Antananarivo & $0.449(0.012)$ & $0.446(0.012)$ & $0.487(0.012)$ & $0.261(0.011)$ & $0.486(0.033)$ \\
Fianarantsoa & $0.613(0.018)$ & $0.559(0.018)$ & $0.730(0.016)$ & $0.364(0.017)$ & $0.691(0.046)$ \\
Toamasina & $0.649(0.018)$ & $0.539(0.019)$ & $0.755(0.016)$ & $0.541(0.019)$ & $0.725(0.040)$ \\
Mahajanga & $0.483(0.020)$ & $0.546(0.019)$ & $0.696(0.018)$ & $0.534(0.019)$ & $0.762(0.043)$ \\
Antsiranana & $0.531(0.019)$ & $0.590(0.019)$ & $0.644(0.018)$ & $0.494(0.019)$ & $0.819(0.040)$ \\
Toliara & $0.443(0.021)$ & $0.504(0.021)$ & $0.627(0.020)$ & $0.345(0.020)$ & $0.832(0.037)$ \\
\hline Madagascar & $0.531(0.019)$ & $0.521(0.019)$ & $0.638(0.018)$ & $0.399(0.018)$ & $0.697(0.015)$ \\
\hline \hline
\end{tabular}

Table 3: Proportion of households that consider their level of expenditure inadequate by household type and consumption category (standard errors)

\begin{tabular}{lccccc}
\hline \multicolumn{5}{c}{ Adequacy of household expenditures } \\
\hline Household type $^{\text {a }}$ & Food & Housing & Clothing & Health & Objective poverty \\
\hline Elderly & $0.525(0.054)$ & $0.430(0.054)$ & $0.535(0.054)$ & $0.486(0.054)$ & $0.352(0.101)$ \\
Single Parent & $0.660(0.020)$ & $0.546(0.021)$ & $0.735(0.019)$ & $0.480(0.021)$ & $0.788(0.049)$ \\
Nuclear & $0.533(0.009)$ & $0.547(0.009)$ & $0.654(0.009)$ & $0.386(0.009)$ & $0.735(0.021)$ \\
Extended & $0.636(0.049)$ & $0.543(0.051)$ & $0.712(0.046)$ & $0.424(0.051)$ & $0.876(0.090)$ \\
More than 3 children & $0.611(0.014)$ & $0.570(0.014)$ & $0.717(0.013)$ & $0.437(0.014)$ & $0.834(0.024)$ \\
\hline Total & $0.531(0.019)$ & $0.521(0.019)$ & $0.638(0.018)$ & $0.399(0.018)$ & $0.697(0.015)$ \\
\hline \hline
\end{tabular}

${ }^{\mathrm{a}}$ Definition of household types: elderly - households comprising of people age 60 and older; single parent - families of a single parent with children; nuclear family - family with two parents and one or two children; extended family - households where several generations reside together. 
Table 4: Summary statistics

\begin{tabular}{|c|c|c|c|}
\hline Variable & $\mathrm{N}$ & Mean & Std. Dev. \\
\hline \multicolumn{4}{|l|}{ Welfare Indicators } \\
\hline Log of total expenditure & 5092 & 15.225 & 0.837 \\
\hline Log food consumption & 5092 & 14.725 & 0.749 \\
\hline Log housing consumption & 5088 & 12.869 & 1.080 \\
\hline Log clothing consumption & 4524 & 11.921 & 1.224 \\
\hline \multicolumn{4}{|l|}{ Household Characteristics } \\
\hline Log household size & 5092 & 1.375 & 0.563 \\
\hline Share of children aged [0-6] & 5092 & 0.187 & 0.197 \\
\hline Share of children aged [7-14] & 5092 & 0.165 & 0.189 \\
\hline Share of elderly aged $>59$ & 5092 & 0.064 & 0.187 \\
\hline Share of men aged [15-24] & 5092 & 0.113 & 0.171 \\
\hline Share of men aged [20-59] & 5092 & 0.202 & 0.189 \\
\hline Share of women aged [20-59] & 5092 & 0.179 & 0.178 \\
\hline Share of women aged [15-24] & 5092 & 0.089 & 0.162 \\
\hline \multicolumn{4}{|l|}{ Education } \\
\hline Share not educated & 5092 & 0.338 & 0.313 \\
\hline Share with primary schooling & 5092 & 0.170 & 0.241 \\
\hline Share with secondary schooling & 5092 & 0.088 & 0.185 \\
\hline Share with high school & 5092 & 0.046 & 0.142 \\
\hline Share with university level & 5092 & 0.020 & 0.096 \\
\hline \multicolumn{4}{|l|}{ Work status } \\
\hline Share of employed & 5092 & 0.492 & 0.295 \\
\hline Share of unemployed & 5092 & 0.031 & 0.112 \\
\hline Share of employed in agriculture & 5092 & 0.269 & 0.340 \\
\hline Share of sick & 5092 & 0.126 & 0.219 \\
\hline \multicolumn{4}{|l|}{ Religion } \\
\hline Traditional & 5092 & 0.157 & --- \\
\hline Hindu & 5092 & & --- \\
\hline Catholic & 5092 & 0.339 & --- \\
\hline Protestant & 5092 & 0.326 & --- \\
\hline Muslim & 5092 & 0.016 & --- \\
\hline Other religion & 5092 & 0.057 & --- \\
\hline \multicolumn{4}{|l|}{ Local Characteristics } \\
\hline Mean log consumption of cluster & 5092 & 15.228 & 0.624 \\
\hline Gini of cluster & 5093 & 0.290 & 0.073 \\
\hline Rural & 5093 & 0.401 & --- \\
\hline Antananarivo & 5093 & 0.331 & --- \\
\hline Fianarantsoa & 5093 & 0.149 & -- \\
\hline Toamasina & 5093 & 0.143 & --- \\
\hline Mahajanga & 5093 & 0.129 & --- \\
\hline Antsiranana & 5093 & 0.113 & --- \\
\hline Toliara & 5093 & 0.133 & --- \\
\hline
\end{tabular}


Table 5: Ordered Probit estimation of the determinants of CAQ responses

\begin{tabular}{|c|c|c|c|c|c|c|c|c|}
\hline & \multicolumn{6}{|c|}{ Method $1 \mathrm{~A}$} & \multirow{2}{*}{\multicolumn{2}{|c|}{$\begin{array}{c}\text { Method } 2 \\
\text { Food }\end{array}$}} \\
\hline & \multicolumn{2}{|c|}{ Food } & \multicolumn{2}{|c|}{ Housing } & \multicolumn{2}{|c|}{ Clothing } & & \\
\hline & Coefficient & S.E. & Coefficient & S.E. & Coefficient & S.E. & Coefficien & S.E. \\
\hline \multicolumn{9}{|l|}{ Consumption } \\
\hline Log total consumption & & & & & & & $0.505^{\star * *}$ & 0.037 \\
\hline Log food consumption & $0.201^{* \star *}$ & 0.039 & 0.047 & 0.039 & $0.166^{* * *}$ & 0.041 & & \\
\hline Log housing consumption & $0.278^{* * *}$ & 0.029 & $0.369^{* * *}$ & 0.030 & $0.304^{* * *}$ & 0.030 & & \\
\hline Log clothing consumption & $0.074^{* * *}$ & 0.018 & 0.006 & 0.019 & $0.121^{* * *}$ & 0.020 & & \\
\hline \multicolumn{9}{|l|}{ Demographic Characteristics } \\
\hline Log household size & $-0.387^{\star \star \star}$ & 0.049 & $-0.138^{* * *}$ & 0.049 & $-0.326^{* \star *}$ & 0.052 & $-0.420^{* * *}$ & 0.045 \\
\hline Share of children aged [0-6] & 0.249 & 0.160 & -0.230 & 0.162 & $0.315^{\star}$ & 0.169 & 0.202 & 0.148 \\
\hline Share of children aged [7-14] & 0.007 & 0.164 & -0.156 & 0.165 & 0.075 & 0.173 & -0.104 & 0.151 \\
\hline Share of women aged [15-24] & $0.248^{*}$ & 0.149 & 0.026 & 0.151 & 0.089 & 0.158 & 0.174 & 0.136 \\
\hline Share of women aged [20-59] & 0.211 & 0.141 & -0.119 & 0.143 & 0.214 & 0.149 & 0.163 & 0.130 \\
\hline Share of men aged [15-24] & 0.057 & 0.128 & -0.157 & 0.130 & -0.043 & 0.136 & -0.030 & 0.120 \\
\hline Share of men aged [25-59] & \multicolumn{8}{|c|}{ Reference } \\
\hline Share of elderly aged > 59 & -0.115 & 0.145 & $0.381^{* \star *}$ & 0.144 & $0.320^{\star *}$ & 0.151 & -0.075 & 0.127 \\
\hline Share not educated & \multicolumn{8}{|c|}{ Reference } \\
\hline Share with primary schooling & $0.237^{\star \star *}$ & 0.090 & $0.380^{* * *}$ & 0.091 & $0.444^{* \star *}$ & 0.094 & $0.291^{* * *}$ & 0.083 \\
\hline Share with secondary schooling & $0.209^{*}$ & 0.116 & $0.496^{* * *}$ & 0.118 & $0.519^{* * *}$ & 0.120 & $0.307^{* *}$ & 0.107 \\
\hline Share with high school & $0.444^{* * *}$ & 0.145 & $0.348^{* *}$ & 0.147 & $0.469^{* * *}$ & 0.151 & $0.534^{* * *}$ & 0.138 \\
\hline Share with university level & 0.320 & 0.203 & $0.687^{* * *}$ & 0.205 & $0.684^{* * *}$ & 0.213 & 0.467 & 0.191 \\
\hline Share employed & 0.084 & 0.093 & $-0.315^{\star \star \star}$ & 0.093 & 0.027 & 0.098 & 0.040 & 0.085 \\
\hline Share unemployed & $-0.371^{* *}$ & 0.176 & -0.039 & 0.175 & -0.192 & 0.181 & -0.218 & 0.162 \\
\hline Share agricultural employment & -0.072 & 0.089 & $0.420^{* * *}$ & 0.090 & -0.004 & 0.095 & -0.091 & 0.081 \\
\hline Share sick & $-0.203^{* *}$ & 0.088 & $-0.100^{* \star}$ & 0.089 & $-0.236^{* *}$ & 0.094 & $-0.257^{* *}$ & 0.081 \\
\hline \multicolumn{9}{|l|}{ Religion dummies } \\
\hline Catholic & \multicolumn{8}{|c|}{ Reference } \\
\hline Traditional & -0.042 & 0.063 & -0.075 & 0.063 & -0.100 & 0.069 & -0.003 & 0.058 \\
\hline Protestant & 0.016 & 0.043 & 0.056 & 0.043 & 0.086 & 0.044 & 0.010 & 0.040 \\
\hline Muslim & -0.090 & 0.146 & 0.053 & 0.147 & 0.122 & 0.151 & -0.040 & 0.137 \\
\hline Hindu & -0.279 & 0.592 & -0.573 & 0.670 & 0.611 & 0.657 & -0.222 & 0.593 \\
\hline Other & -0.018 & 0.083 & -0.062 & 0.084 & -0.024 & 0.088 & -0.003 & 0.076 \\
\hline \multicolumn{9}{|l|}{ Regional characteristics } \\
\hline Mean log consumption of cluster & $-0.273^{\star \star \star}$ & 0.053 & $-0.380^{* * *}$ & 0.053 & $-0.202^{* * *}$ & 0.056 & $-0.300^{* * *}$ & 0.050 \\
\hline Gini of cluster & $-0.653^{* *}$ & 0.256 & -0.186 & 0.257 & -0.079 & 0.270 & $-0.532^{* *}$ & 0.240 \\
\hline Rural & $0.095^{* *}$ & 0.048 & $0.126^{* * *}$ & 0.048 & 0.046 & 0.051 & $0.076^{*}$ & 0.045 \\
\hline Urban & \multicolumn{8}{|c|}{ Reference } \\
\hline Antananarivo & \multicolumn{8}{|c|}{ Reference } \\
\hline Fianarantsoa & -0.026 & 0.063 & 0.065 & 0.063 & $-0.132^{* *}$ & 0.066 & -0.043 & 0.058 \\
\hline Toamasina & -0.025 & 0.066 & 0.030 & 0.066 & $-0.156^{* *}$ & 0.070 & $-0.116^{*}$ & 0.060 \\
\hline Mahajanga & $0.135^{* *}$ & 0.065 & -0.028 & 0.066 & $-0.221^{\star \star \star}$ & 0.069 & $0.127^{* *}$ & 0.061 \\
\hline Antsiranana & $0.135^{* *}$ & 0.065 & -0.048 & 0.066 & -0.022 & 0.068 & 0.077 & 0.060 \\
\hline Toliara & $0.364^{* * *}$ & 0.067 & $0.236^{* * *}$ & 0.068 & -0.014 & 0.070 & $0.271^{* * *}$ & 0.061 \\
\hline \multicolumn{9}{|l|}{ Ancillary Parameters } \\
\hline Cutoff 1 & $2.786^{\star \star \star}$ & 0.734 & -0.390 & 0.737 & $4.685^{\star \star \star}$ & 0.775 & $2.556^{* * *}$ & 0.676 \\
\hline Cutoff 2 & $4.887^{\star \star *}$ & 0.736 & 1.788 & 0.738 & $7.107^{\star \star *}$ & 0.781 & $4.613^{\star \star *}$ & 0.678 \\
\hline Pseudo R2 = & 0.078 & & 0.066 & & 0.131 & & 0.071 & \\
\hline Number of obs = & 4484 & & 4481 & & 4486 & & 5055 & \\
\hline
\end{tabular}

Note: * is significant at $10 \%$ level; $* *$ is significant at $5 \%$ level; *** is significant at $1 \%$ level. 
Table 6: Poverty headcount and poverty headcount ranking by province (bootstrapped standard errors)

\begin{tabular}{lccccccccc}
\hline \multicolumn{7}{c}{ Poverty rates and respective poverty ranks } \\
\hline Province & Objective & Rank & Method 1a & Rank & Method 1b & Rank & Method 2 & Rank \\
\hline Antananarivo & $0.486(0.033)$ & 1 & $0.513(0.033)$ & 1 & $0.465(0.030)$ & 3 & $0.531(0.030)$ & 2 \\
Antsiranana & $0.691(0.046)$ & 2 & $0.970(0.054)$ & 5 & $0.216(0.033)$ & 1 & $0.351(0.046)$ & 1 \\
Mahajanga & $0.725(0.040)$ & 3 & $0.978(0.042)$ & 6 & $0.378(0.039)$ & 2 & $0.593(0.037)$ & 3 \\
Toliara & $0.762(0.043)$ & 4 & $0.830(0.046)$ & 2 & $0.471(0.040)$ & 4 & $0.702(0.033)$ & 4 \\
Toamasina & $0.819(0.040)$ & 5 & $0.940(0.047)$ & 4 & $0.832(0.034)$ & 5 & $0.832(0.033)$ & 5 \\
Fianarantsoa & $0.832(0.037)$ & 6 & $0.925(0.047)$ & 3 & $0.876(0.040)$ & 6 & $0.838(0.035)$ & 6 \\
\hline Madagascar & $0.697(0.015)$ & & $0.800(0.014)$ & & $0.587(0.016)$ & & $0.664(0.016)$ & \\
\hline \hline
\end{tabular}


Table 7: Poverty headcounts by household characteristics and characteristics of household head (bootstrapped standard errors)

\begin{tabular}{|c|c|c|c|c|c|}
\hline & & Objective & $\begin{array}{r}\text { Subjective } \\
\text { Method 1A }\end{array}$ & $\begin{array}{l}\text { Subjective } \\
\text { Method 1B }\end{array}$ & $\begin{array}{l}\text { Subjective } \\
\text { Method } 2\end{array}$ \\
\hline \multicolumn{6}{|c|}{ Household structure } \\
\hline Elderly & & $0.352(0.101)$ & $0.987(0.171)$ & $0.980(0.109)$ & $0.607(0.417)$ \\
\hline Single Parent & & $0.788(0.049)$ & $0.900(0.047)$ & $0.690(0.051)$ & $0.761(0.044)$ \\
\hline Nuclear & & $0.735(0.021)$ & $0.788(0.021)$ & $0.577(0.018)$ & $0.690(0.023)$ \\
\hline $\begin{array}{l}\text { Extended } \\
\text { More than } 3\end{array}$ & & $0.876(0.090)$ & $0.894(0.110)$ & $0.720(0.090)$ & $0.756(0.098)$ \\
\hline Children & & $0.834(0.024)$ & $0.862(0.036)$ & $0.698(0.025)$ & $0.801(0.030)$ \\
\hline \multicolumn{6}{|c|}{ Characteristics of the head } \\
\hline Male & & $0.698(0.018)$ & $0.787(0.019)$ & $0.577(0.016)$ & $0.659(0.022)$ \\
\hline Female & & $0.689(0.037)$ & $0.873(0.135)$ & $0.642(0.040)$ & $0.692(0.042)$ \\
\hline Unemployed & & $0.543(0.126)$ & $0.822(0.126)$ & $0.654(0.129)$ & $0.672(0.125)$ \\
\hline \multicolumn{6}{|l|}{ Age } \\
\hline & $18-24$ & $0.658(0.050)$ & $0.821(0.056)$ & $0.437(0.035)$ & $0.640(0.045)$ \\
\hline & $25-44$ & $0.703(0.019)$ & $0.763(0.023)$ & $0.539(0.021)$ & $0.663(0.020)$ \\
\hline & $45-64$ & $0.701(0.035)$ & $0.815(0.032)$ & $0.636(0.031)$ & $0.684(0.026)$ \\
\hline & More than 64 & $0.673(0.067)$ & $0.924(0.071)$ & $0.807(0.061)$ & $0.699(0.080)$ \\
\hline \multicolumn{6}{|l|}{ Education } \\
\hline & None & $0.793(0.024)$ & $0.894(0.031)$ & $0.742(0.028)$ & $0.803(0.026)$ \\
\hline & Primary & $0.601(0.034)$ & $0.689(0.040)$ & $0.487(0.037)$ & $0.562(0.036)$ \\
\hline & Secondary & $0.406(0.044)$ & $0.510(0.050)$ & $0.317(0.046)$ & $0.353(0.051)$ \\
\hline & High School & $0.277(0.043)$ & $0.432(0.050)$ & $0.207(0.049)$ & $0.199(0.036)$ \\
\hline & University & $0.038(0.018)$ & $0.310(0.063)$ & $0.045(0.027)$ & $0.059(0.025)$ \\
\hline \multicolumn{6}{|l|}{ Sector } \\
\hline & Agriculture & $0.850(0.017)$ & $0.944(0.020)$ & $0.721(0.018)$ & $0.790(0.018)$ \\
\hline & Manufacturing & $0.389(0.034)$ & $0.450(0.037)$ & $0.286(0.037)$ & $0.466(0.039)$ \\
\hline & Services & $0.346(0.031)$ & $0.472(0.033)$ & $0.240(0.027)$ & $0.342(0.029)$ \\
\hline & Public Sector & $0.329(0.043)$ & $0.474(0.060)$ & $0.211(0.039)$ & $0.244(0.050)$ \\
\hline & Other & $0.369(0.059)$ & $0.529(0.064)$ & $0.329(0.055)$ & $0.447(0.060)$ \\
\hline \multicolumn{6}{|l|}{ Ethnic Groups } \\
\hline & Highlands & $0.575(0.027)$ & $0.641(0.025)$ & $0.541(0.023)$ & $0.593(0.026)$ \\
\hline & East & $0.820(0.024)$ & $0.956(0.041)$ & $0.780(0.036)$ & $0.797(0.033)$ \\
\hline & South-East & $0.840(0.048)$ & $0.944(0.049)$ & $0.758(0.049)$ & $0.781(0.036)$ \\
\hline & North & $0.696(0.041)$ & $0.914(0.040)$ & $0.297(0.028)$ & $0.506(0.040)$ \\
\hline & South & $0.790(0.047)$ & $0.883(0.037)$ & $0.482(0.036)$ & $0.705(0.027)$ \\
\hline & Foreigners & $0.178(0.048)$ & $0.620(0.128)$ & $0.099(0.041)$ & $0.276(0.078)$ \\
\hline
\end{tabular}


Table 8: Cramer's V statistics for different methods of poverty categorization

\begin{tabular}{lccccccccc}
\hline & Objective & \multicolumn{3}{c}{ CAQ } & \multicolumn{3}{c}{ GSQ } & MIQ \\
\hline & \multicolumn{1}{c}{ Poverty } & \multicolumn{2}{c}{ Method 1A Method 1B Method 2Method 1A Method 1B Method 2 } \\
\hline $\begin{array}{l}\text { Objective poverty } \\
\text { CAQ }\end{array}$ & 1 & 0.505 & 0.556 & 0.684 & 0.091 & 0.565 & 0.629 & 0.359 \\
Method 1A & 0.505 & 1 & 0.499 & 0.423 & 0.082 & 0.494 & 0.439 & 0.285 \\
Method 1B & 0.556 & 0.499 & 1 & 0.642 & 0.062 & 0.947 & 0.561 & 0.213 \\
Method 2 & 0.684 & 0.423 & 0.642 & 1 & 0.094 & 0.644 & 0.750 & 0.342 \\
GSQ & & & & & & & & \\
Method 1A & 0.091 & 0.082 & 0.062 & 0.094 & 1 & 0.062 & 0.106 & 0.122 \\
Method 1B & 0.565 & 0.494 & 0.947 & 0.644 & 0.062 & 1 & 0.564 & 0.213 \\
Method 2 & 0.629 & 0.439 & 0.561 & 0.750 & 0.106 & 0.564 & 1 & 0.301 \\
MIQ & 0.359 & 0.285 & 0.213 & 0.342 & 0.122 & 0.213 & 0.301 & 1 \\
\hline \hline
\end{tabular}



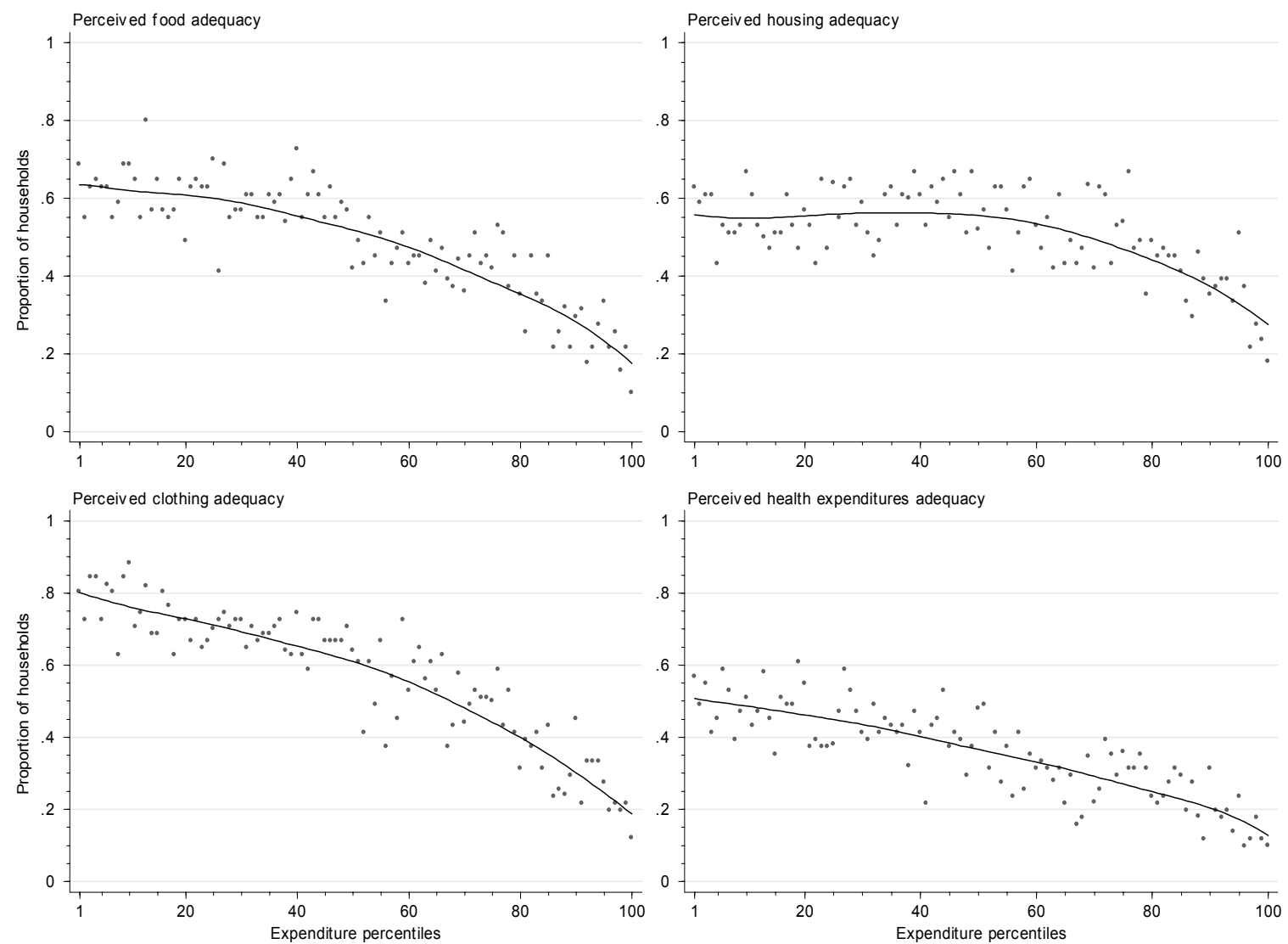

Figure 1: Proportion of households that consider their expenditures inadequate by consumption categories

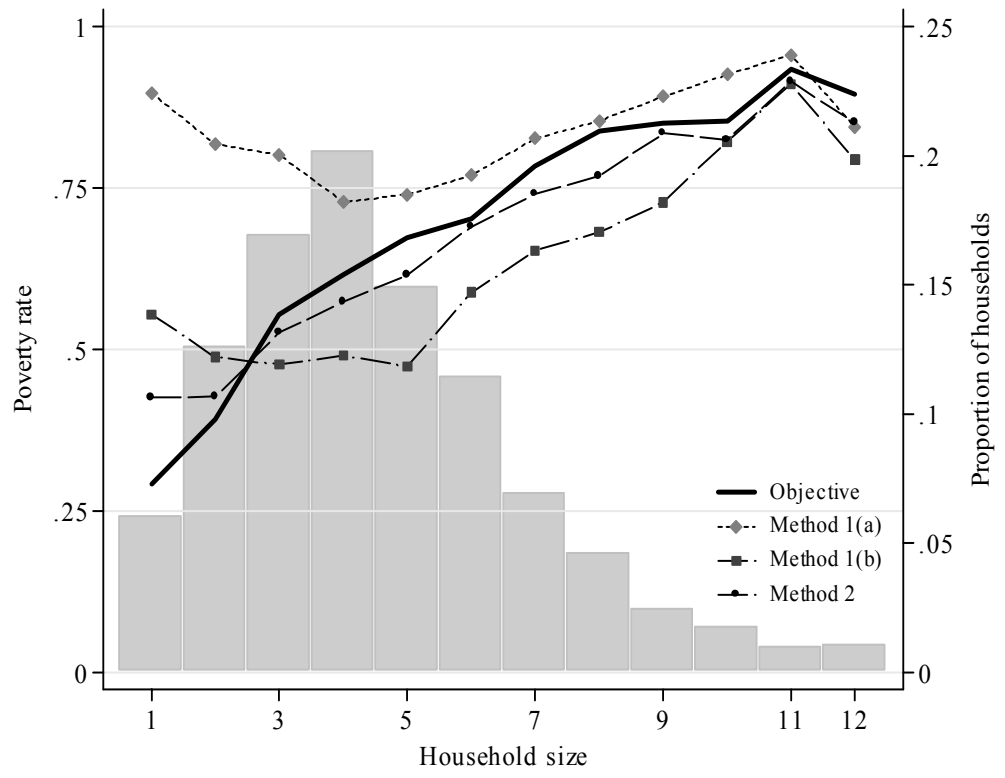

Figure 2: Objective and CAQ subjective poverty rates by household size 


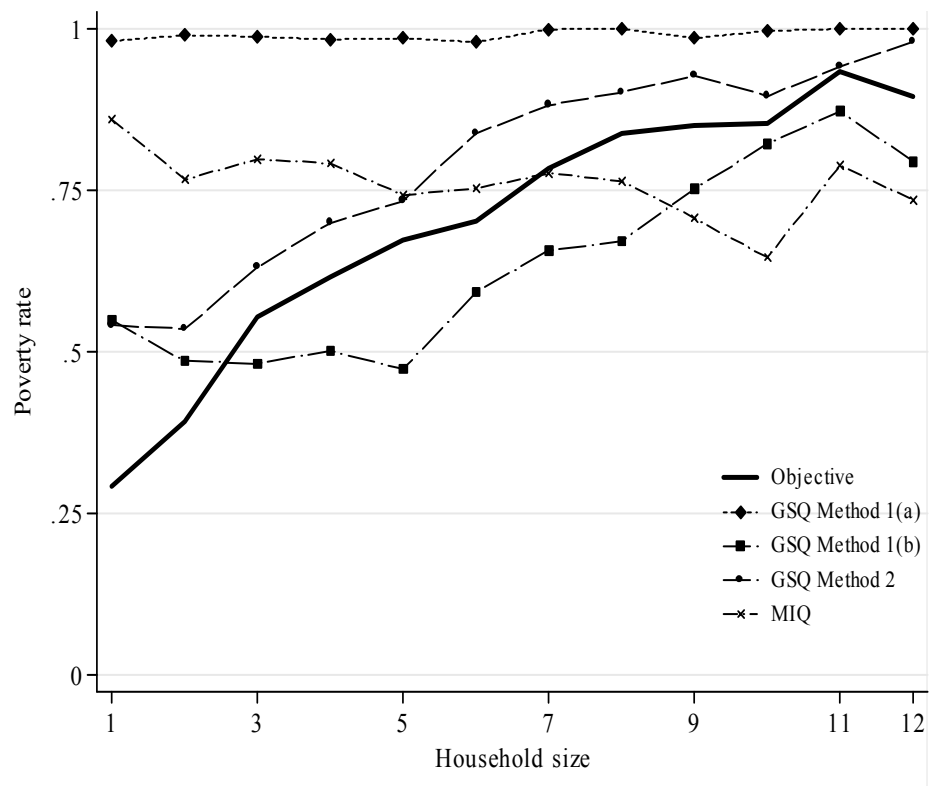

Figure 3: Objective and subjective (GSQ and MIQ) poverty rates by household size 
Appendix

Table A1: Probit estimation for the GSQ

\begin{tabular}{|c|c|c|c|c|c|c|c|c|}
\hline & \multicolumn{6}{|c|}{ Method (1) } & \multirow{2}{*}{\multicolumn{2}{|c|}{$\begin{array}{c}\text { Method (2) } \\
\text { Food }\end{array}$}} \\
\hline & \multicolumn{2}{|c|}{ Food } & \multicolumn{2}{|c|}{ Housing } & \multicolumn{2}{|c|}{ Clothing } & & \\
\hline & Coefficien & nt S.E. & Coefficient & S.E. & Coefficient & S.E. & Coefficient & S.E. \\
\hline \multicolumn{9}{|l|}{ Consumption } \\
\hline log total consumption & & & & & & & $0.461^{* \star \star}$ & 0.040 \\
\hline log food consumption & $0.180^{* * *}$ & 0.041 & 0.038 & 0.041 & $0.270^{* * *}$ & 0.045 & & \\
\hline log housing consumption & $0.217^{* \star *}$ & 0.031 & $0.371^{* \star *}$ & 0.031 & $0.259^{* * *}$ & 0.032 & & \\
\hline log clothing consumption & $0.075^{* * *}$ & 0.020 & 0.002 & 0.019 & $0.086^{* * *}$ & 0.021 & & \\
\hline \multicolumn{9}{|l|}{ Demographic Characteristics } \\
\hline log household size & $-0.408^{* * *}$ & 0.052 & $-0.119^{* *}$ & 0.051 & $-0.477^{\star \star \star}$ & 0.056 & $-0.466^{* * *}$ & 0.048 \\
\hline Share of children aged [0-6] & $0.608^{* * *}$ & 0.172 & -0.165 & 0.169 & $0.340^{*}$ & 0.180 & $0.562^{* * *}$ & 0.158 \\
\hline Share of children aged [7-14] & 0.166 & 0.176 & -0.196 & 0.173 & 0.137 & 0.184 & 0.115 & 0.161 \\
\hline Share of women aged [15-24] & 0.244 & 0.162 & -0.165 & 0.159 & 0.141 & 0.167 & 0.214 & 0.148 \\
\hline Share of women aged [20-59] & $0.259^{*}$ & 0.154 & 0.000 & 0.150 & 0.158 & 0.157 & $0.267^{*}$ & 0.143 \\
\hline Share of men aged [15-24] & 0.233 & 0.138 & 0.033 & 0.136 & 0.093 & 0.143 & 0.202 & 0.130 \\
\hline Share of men aged [25-59] & \multicolumn{8}{|c|}{ Reference } \\
\hline Share of elderly aged $>59$ & -0.079 & 0.155 & $0.296^{*}$ & 0.154 & -0.055 & 0.164 & 0.036 & 0.136 \\
\hline Share not educated & \multicolumn{8}{|c|}{ Reference } \\
\hline Share with primary schooling & $0.310^{\star \star \star}$ & 0.096 & $0.204^{* *}$ & 0.096 & $0.224^{* *}$ & 0.099 & $0.334^{* \star *}$ & 0.089 \\
\hline Share with secondary schooling & $0.478^{* * *}$ & 0.126 & $0.272^{* *}$ & 0.124 & $0.421^{* * *}$ & 0.126 & $0.513^{* * *}$ & 0.117 \\
\hline Share with high school & $0.635^{* * *}$ & 0.164 & 0.126 & 0.158 & $0.396^{* *}$ & 0.159 & $0.689^{* * *}$ & 0.157 \\
\hline Share with university level & $0.660^{\star \star *}$ & 0.237 & $0.551^{\star *}$ & 0.229 & $0.861^{* * *}$ & 0.237 & $0.715^{* \star *}$ & 0.224 \\
\hline Share employed & 0.018 & 0.100 & $-0.291^{* * *}$ & 0.099 & -0.086 & 0.105 & -0.014 & 0.091 \\
\hline Share unemployed & $-0.411^{* *}$ & 0.190 & -0.091 & 0.188 & $-0.448^{* *}$ & 0.194 & $-0.285^{\star}$ & 0.175 \\
\hline Share agricultural employment & $0.157^{\star}$ & 0.095 & $0.497^{* * *}$ & 0.094 & -0.044 & 0.100 & 0.096 & 0.087 \\
\hline Share sick & $-0.163^{*}$ & 0.093 & -0.028 & 0.092 & $-0.248^{* *}$ & 0.100 & $-0.199^{* *}$ & 0.086 \\
\hline \multicolumn{9}{|l|}{ Religion dummies } \\
\hline Catholic & \multicolumn{8}{|c|}{ Reference } \\
\hline Traditional & -0.061 & 0.066 & $-0.207^{* * *}$ & 0.065 & -0.103 & 0.074 & -0.044 & 0.062 \\
\hline Protestant & $0.122^{* * *}$ & 0.045 & 0.055 & 0.045 & $0.108^{* *}$ & 0.047 & $0.107^{* *}$ & 0.043 \\
\hline Muslim & 0.023 & 0.157 & 0.191 & 0.157 & 0.005 & 0.163 & 0.101 & 0.149 \\
\hline Hindu & -0.538 & 0.701 & -0.333 & 0.718 & -0.145 & 0.789 & -0.481 & 0.690 \\
\hline Other & -0.033 & 0.088 & -0.115 & 0.088 & 0.026 & 0.093 & -0.016 & 0.081 \\
\hline \multicolumn{9}{|l|}{ Regional characteristics } \\
\hline Mean log consumption of cluster & $-0.259^{* * *}$ & 0.056 & $-0.402^{* * *}$ & 0.056 & $-0.200^{* * *}$ & 0.059 & $-0.313^{* * *}$ & 0.053 \\
\hline Gini of cluster & -0.733 & 0.272 & -0.986 & 0.271 & 0.204 & 0.288 & $-0.657^{* *}$ & 0.255 \\
\hline Rural & $-0.098^{* *}$ & 0.050 & -0.033 & 0.050 & 0.047 & 0.054 & $-0.076^{\star}$ & 0.047 \\
\hline Urban & \multicolumn{8}{|c|}{ Reference } \\
\hline Antananarivo & \multicolumn{8}{|c|}{ Reference } \\
\hline Fianarantsoa & $-0.243^{* * *}$ & 0.067 & -0.041 & 0.066 & $-0.189^{* * *}$ & 0.070 & $-0.244^{* * *}$ & 0.062 \\
\hline Toamasina & $-0.170^{* *}$ & 0.070 & -0.058 & 0.069 & $-0.233^{* * *}$ & 0.075 & $-0.236^{* * *}$ & 0.063 \\
\hline Mahajanga & $0.123^{*}$ & 0.069 & -0.063 & 0.069 & -0.096 & 0.073 & $0.152^{* *}$ & 0.065 \\
\hline Antsiranana & $-0.115^{*}$ & 0.069 & -0.057 & 0.068 & $-0.138^{*}$ & 0.073 & $-0.149^{* *}$ & 0.064 \\
\hline Toliara & $0.195^{* * *}$ & 0.072 & $0.135^{*}$ & 0.071 & -0.042 & 0.074 & $0.132^{* *}$ & 0.066 \\
\hline Constant & -2.044 & 0.780 & 1.194 & 0.773 & -5.288 & 0.828 & -1.793 & 0.720 \\
\hline Pseudo R2 & 0.088 & & 0.060 & & 0.132 & & 0.084 & \\
\hline Number of obs & 4490 & & 4486 & & 4486 & & 5061 & \\
\hline
\end{tabular}


Table A2: Minimum Income Question Regression

\begin{tabular}{|c|c|c|}
\hline & \multicolumn{2}{|c|}{ Minimum Income Question } \\
\hline & Coefficient & Std. Err. \\
\hline \multicolumn{3}{|l|}{ Consumption } \\
\hline log total consumption & $0.409^{* *}$ & 0.020 \\
\hline \multicolumn{3}{|l|}{ Demographic Characteristics } \\
\hline log household size & $0.260^{* *}$ & 0.024 \\
\hline Share of children aged [0-6] & $-0.210^{* * *}$ & 0.080 \\
\hline Share of children aged [7-14] & $-0.155^{*}$ & 0.082 \\
\hline Share of women aged [15-24] & $-0.226^{* *}$ & 0.075 \\
\hline Share of women aged [20-59] & 0.072 & 0.072 \\
\hline Share of men aged [15-24] & $-0.168^{* *}$ & 0.066 \\
\hline Share of men aged [25-59] & \multicolumn{2}{|r|}{ Reference } \\
\hline Share of elderly aged $>59$ & -0.046 & 0.069 \\
\hline Share not educated & \multicolumn{2}{|r|}{ Reference } \\
\hline Share with primary schooling & $0.201^{* * *}$ & 0.046 \\
\hline Share with secondary schooling & $0.381^{* * *}$ & 0.059 \\
\hline Share with high school & $0.418^{* * *}$ & 0.077 \\
\hline Share with university level & $0.656^{* * *}$ & 0.109 \\
\hline Share employed & $0.092^{* *}$ & 0.046 \\
\hline Share unemployed & -0.015 & 0.088 \\
\hline Share agricultural employment & $-0.290^{* * *}$ & 0.044 \\
\hline Share sick & 0.008 & 0.044 \\
\hline \multicolumn{3}{|l|}{ Religion dummies } \\
\hline Catholic & \multicolumn{2}{|r|}{ Reference } \\
\hline Traditional & $0.085^{* * *}$ & 0.031 \\
\hline Protestant & -0.011 & 0.022 \\
\hline Muslim & $0.167^{* *}$ & 0.076 \\
\hline Hindu & -0.111 & 0.382 \\
\hline Other & 0.067 & 0.041 \\
\hline \multicolumn{3}{|l|}{ Regional characteristics } \\
\hline Mean log consumption of cluster & $0.163^{* * *}$ & 0.027 \\
\hline Rural & $-0.132^{* * *}$ & 0.024 \\
\hline Urban & \multicolumn{2}{|c|}{ Reference } \\
\hline Antananarivo & \multicolumn{2}{|r|}{ Reference } \\
\hline Fianarantsoa & $-0.097^{* * *}$ & 0.031 \\
\hline Toamasina & -0.009 & 0.032 \\
\hline Mahajanga & $0.065^{* *}$ & 0.033 \\
\hline Antsiranana & $0.256^{* * *}$ & 0.033 \\
\hline Toliara & $0.234^{* * *}$ & 0.034 \\
\hline Gini of cluster & $0.588^{* * *}$ & 0.131 \\
\hline Constant & 6.277 & 0.367 \\
\hline Adiusted $\mathrm{R}^{2}$ & 0.482 & \\
\hline Number of observations & 5003 & \\
\hline
\end{tabular}

